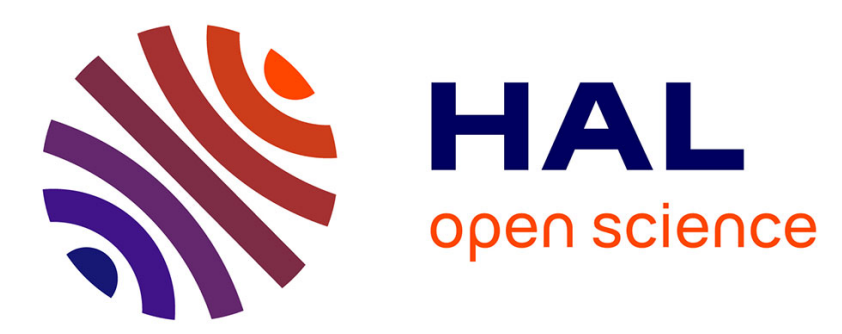

\title{
Onera Campaign in South Greenland for Imaging of Snow/Ice Subsurface Features from Airborne SAR
}

\author{
Hubert M.J. Cantalloube
}

\section{To cite this version:}

Hubert M.J. Cantalloube. Onera Campaign in South Greenland for Imaging of Snow/Ice Subsurface Features from Airborne SAR. 2019 International Radar Conference (RADAR), Sep 2019, TOULON, France. pp.1-6, 10.1109/RADAR41533.2019.171403 . hal-03306593

\section{HAL Id: hal-03306593 https://hal.science/hal-03306593}

Submitted on 29 Jul 2021

HAL is a multi-disciplinary open access archive for the deposit and dissemination of scientific research documents, whether they are published or not. The documents may come from teaching and research institutions in France or abroad, or from public or private research centers.
L'archive ouverte pluridisciplinaire HAL, est destinée au dépôt et à la diffusion de documents scientifiques de niveau recherche, publiés ou non, émanant des établissements d'enseignement et de recherche français ou étrangers, des laboratoires publics ou privés. 


\title{
ONERA CAMPAIGN IN SOUTH GREENLAND FOR IMAGING OF SNOW/ICE SUBSURFACE FEATURES FROM AIRBORNE SAR
}

\author{
Hubert M.J. Cantalloube \\ dept. of electromagnetic \& radar \\ ONERA, Université Paris Saclay \\ F-91123 Palaiseau, France \\ cantallo@onera.fr
}

\begin{abstract}
An acquisition campaign of the ONERA airborne synthetic aperture radar system RAMSES have been set up on the the Greenland ice-shelf to assess the detectability of buried object and subsurface features through dry snow/ice cover. Three bands where investigated UHF, $L$ and $X$ band expecting a tradeoff between cover penetration and target radar cross-section, the latter being critical due to the expected high clutter radar cross-section. Four sites were imaged, a calibration zone and a front glacier close to Kangerlussuaq, a dry accumulation zone North of the polar circle, a percolated accumulation zone East of Narsassuaq, and an intermediate zone between accumulation and ablation zone. The engine fragment plume of the unconfined engine \#4 failure of the F-HPJE (about 190 days earlier) was in the middle of the percolated accumulation zone, providing several known buried fragments, as well as opportunities to unravel unknown buried fragments that may have an interest for the engine failure investigation. Test objects (corner reflectors, Luneburg lens, ice filed plastic sled, snow refilled hole) have been setup at known positions and depths to assess detection through cover and ice drift rates. Processing of the data confirmed the high clutter return, the better penetration at low (UHF) band and the higher radar cross-section at high $(\mathrm{X})$ band. However, the setup targets radar cross-section presented an unexpected considerable attenuation that prompted the use of $\mathrm{X}$-band and intensive processing to detect buried targets.
\end{abstract}

Index Terms-Ground penetration radar, snow, ice, stereo radar imaging

\section{INTRODUCTION}

Icecaps and ice-shelves present an high radar cross section (RCS) that was not expected for a smooth terrain. Indeed, for both soil/stone covered terrain or water surface, RCS is increasing with surface roughness (think of wind inversion from radar images commonly used on oceans). High icecaps RCS was first discovered on icy celestial bodies in the 70's: Radar observation of Jupiter satellites from Arecibo telescope revealed the extremely high RCS of the icy words Europe, Ganymede \& Callisto compared with the telluric Io [1]. The origin of this high RCS is supposedly the wave penetration in

Thanks to DGAC/BEA (French Accident Board of the Civilian Air Directorate) for funding, to the Danish GEUS and Arctic Command for the valuable ground truth, target setup \& operational support. ICEsat DEM are provided by the Polar Geospatial Centre under NSF OPP awards 1043681, $1559691 \&$ 1542736 the low conductivity snow and/or ice, that allows significant build-up of radar return through moderate returns on a large number of layered inhomogeneities. This was later corroborated by comparing the ice shelf altitude derived from LIDAR measurement and radar interferometry. The "radar" terrain surface appears a few (tens of) meter below the "optical" surface [2].

After the unconfined engine \#4 failure of the F-HPJE over Greenland (fig. 1), most engine fragments have been found from helicopter overflight, observed and most of them recovered for forensic examination.

However, at least one fragment, critical for understanding failure mechanism, was not found in the fragment plume. This fragment (the axis of the fan assembly) was later suspected to have fallen upwind due to a much lower air drag coefficient than the fan blades and casing fragments.

A couple of optical space observation 12 and 15 days after the incident are available, but did not yield (to date) any new fragment localisation. In fact, only one big fragment (not recovered) is detected from space (fig. 2).

Due to a heavy snowfall that forbid any further visual detection of new fragment 24 days after the incident, the idea of using radar to search the missing fragment through the snow/ice ground was proposed to ONERA. However, due to the polar winter, radar campaign had to wait until the following spring, when the targets were covered with 1 to $2 \mathrm{~m}$ of snow and ice fallen during the winter season.

\section{EXPERIMENTAL SETUP}

\section{A. Sensors}

The RAMSES SAR system is operated from a small corporate twin jet aircraft (a Falcon 20). Radar front-ends are installed in two pods under each wing. For the Greenland campaign, the right wing pod contained the wide beam $\mathrm{X}$ band component in the front and the L band component in the back and the left pod contained the UHF component (fig. 3).

For data rate considerations, the flights were separated into $\mathrm{X}$-band right-looking acquisition sequences and simultaneous L+UHF bands left looking acquisition sequences. Waveforms are summarised in table I. All waveforms use linear frequency 


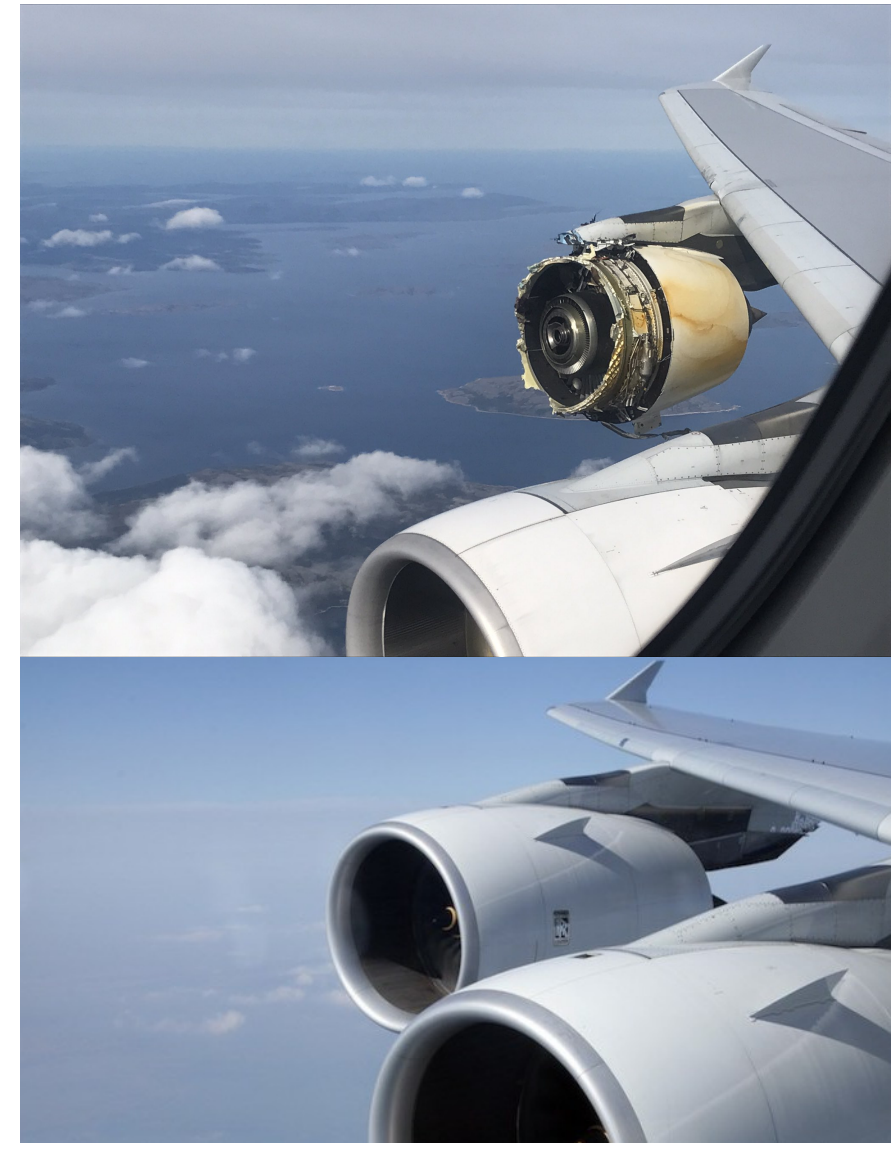

Fig. 1. F-HPJE engine \#4 after unconfined failure (top) and image of a similar engine showing the missing fan assembly part (bottom).
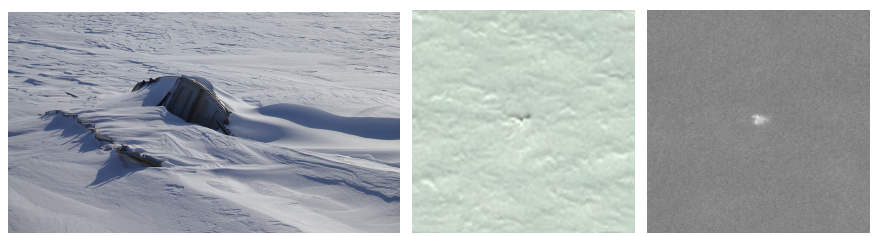

Fig. 2. Large fragment \#4 (not recovered) seen from ground 5 days after fallout (left), seen from the Pleiade satellite 12 days after fallout (middle), and through the snow/ice from RAMSES at X-band 190 days after fallout (right).

modulation.

The X-band back-end has a transmit capacity from 8 to 12 $\mathrm{GHz}$, but beyond $720 \mathrm{MHz}$ of bandwidth, it must transmit the full bandwidth in successive linear frequency modulation pulses (frequency agility technique). With the wide beam front-end, the lower Doppler ambiguity margin forbids using frequency agility together with alternating polarisation transmit. The polarisation variety was favoured against higher range resolution because target detectability could more strongly depend on the polarisation (due to its unknown orientation in space) than on frequency. Simultaneous higher range resolution and polarisation variety is possible using the narrow beam front-end, but to the expense of a much

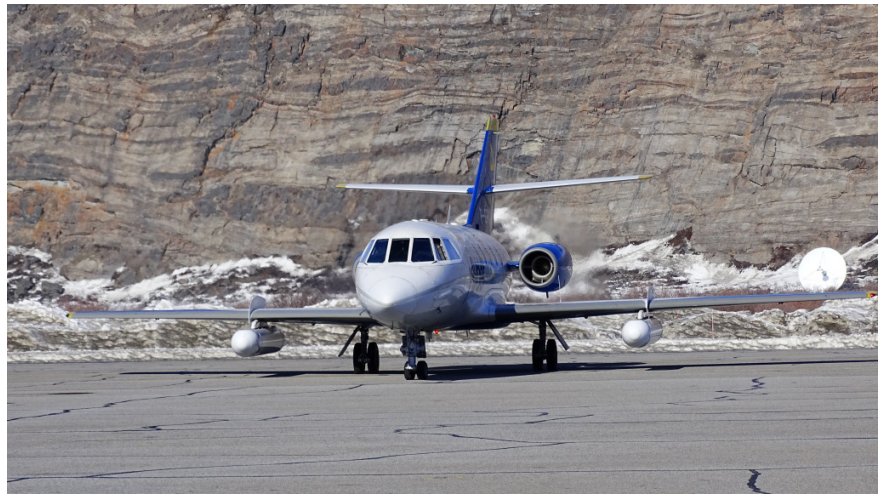

Fig. 3. ONERA SAR system "RAMSES" in the configuration used in Greenland. Pod under left wing (here on the right) contains the UHF sensor. Pod under the right wing (here on the left) contains the X-band sensor fore and the L band sensor aft. X-band sensor looks to the right (starboard) while both L \& UHF band sensors look to the left (port).

narrower useful swath.

However, operational safety and meteorological issues, linked to the distance between the airport and the only backup runway and the severe weather conditions, drastically limited the acquisition time on site per flight as well as the possible fly days. For that reason, the narrow swath X-band alternative was discarded and the wide band antenna was used.

TABLE I

GREENLAND CAMPAIGN WAVEFORMS

\begin{tabular}{cccccc}
\hline band & $\begin{array}{c}\text { centre frequ. } \\
(\mathrm{GHz})\end{array}$ & $\begin{array}{c}\text { bandwidth } \\
(\mathrm{MHz})\end{array}$ & $\begin{array}{c}\text { Tx } \\
\text { sequence }\end{array}$ & $\begin{array}{c}\text { Rx } \\
\text { sequence }\end{array}$ & $\begin{array}{c}\text { PRF } \\
(\mathrm{kHz})\end{array}$ \\
\hline $\mathrm{X}$ & 9.575 & 720 & $\mathrm{~V} \mathrm{H}$ & $\mathrm{Vh}+\mathrm{Vv} \mathrm{Hh}+\mathrm{Vv}$ & 4 \\
\hline \hline $\mathrm{L}$ & 1.325 & 150 & $\mathrm{~V} \mathrm{H}$ & $\mathrm{Vh}+\mathrm{Vv} \mathrm{Hh+Vv}$ & 4 \\
\hline $\mathrm{UHF}$ & 0.341 & 238 & V V H H & Vh Vv Hh Hv & 2 \\
\hline
\end{tabular}

\section{B. calibration setup}

For calibration of the internal delays, a corner reflector was set close to the Kangerlussuaq airport (fig. 4). Its position was accurately measured using differential GPS, allowing delay calibration beyond the nanosecond accuracy.

Close to the target search area, a similar corner reflector was buried under packed snow at a depth comparable to the expected target depth. A few artefacts were also added: Part of a fan axis from a slightly smaller engine (emulating the target engine fragment), a plastic sled filled with ice (emulating an ice lens, a natural occurring feature in percolation glacier zone), a large hole refilled with packed snow. For image registration purpose, a Luneburg lens reflector was half buried at a known position.

The Luneburg lens was expected to provide a single point echo visible from any position at a fixed (in fact slowly drifting with ice flow) position. However, snow fall completely covered it within a few days, ruining the possibility to use it for that purpose. Use of internal calibrating signals and better than 
expected GPS ionospheric correction eventually made image registration unnecessary.

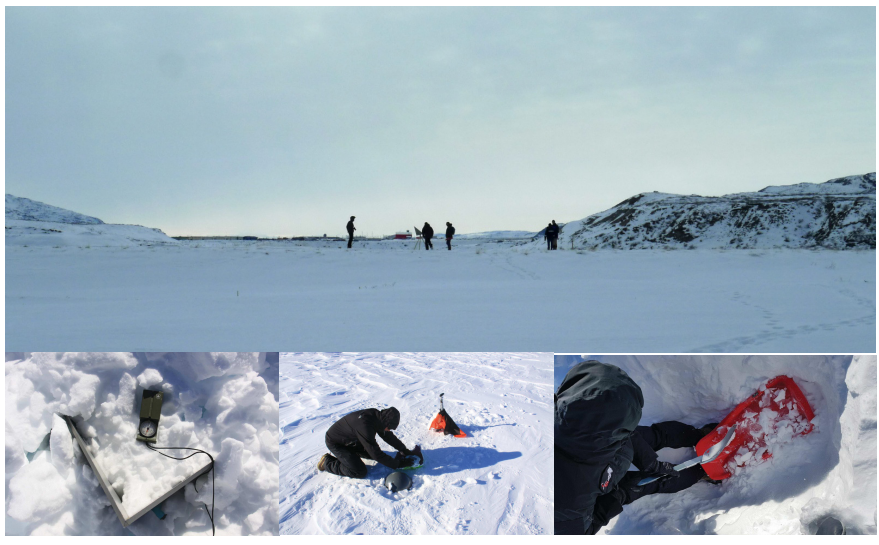

Fig. 4. Target setup: Calibrating corner reflector set in Kangerlussuaq (top). Corner reflector during burial (bottom left), Luneburg sphere half buried (bottom centre) and ice lens emulation during fabrication (bottom right).

The Luneburg lens has a peak RCS of 16.4. $\mathrm{dBm}^{2}$ and the corner reflector a peak RCS of $26.7 \mathrm{dBm}^{2}$ at X-band (their designed frequency band). At L and UHF bands, the corner reflector has a peak RCS of 9 and $4.3 \mathrm{dBm}^{2}$ respectively (it does not follow the square frequency rule because it is too small for GO approximation to hold at lower bands).

Undamaged fan blade and fan axis have also been imaged in France during the campaign preparation in order to has an idea of the target fragments RCS. Though significantly varying with presentation, the RCS of a complete undamaged blade is 0 to $1 \mathrm{dBm}^{2}$ and that of the complete axis is around $-4 \mathrm{dBm}^{2}$ at $\mathrm{X}$-band. Hence the part of fan axis in the ground setup should have a RCS around $-16 \mathrm{dBm}^{2}$ when not buried. As we shall see, the actual RCS when buried under snow/ice mixture is much lower (and not proportional to the "naked" RCS).

\section{PEnEtration ASSESSMENT FROM NADIR LOOKING (SOUNDING) MODE}

Antennae of the system were of course pointed to the side (with $45^{\circ}$ off-nadir angle at UHF \& L-bands, with $60^{\circ}$ or $40^{\circ}$ off-nadir angle at X-band). However the beam width was wide enough at low frequency to significantly illuminate the nadir. At X-band, a significant side lobe at $\mathrm{V}$ polarisation allowed to image to the nadir. Synthetic aperture image at the nadir yield images with depth resolution (range axis) and along track resolution (azimuth axis), but no cross-track resolution, hence it is only useful to detect features extended across-track, such as horizontal density discontinuities and crevices transversal to the flight line (fig. 5).

Several horizontal layers of denser ice occur naturally within the upper ice-shelf. These are due to the alternation of surface melting and water percolation during summer and refreeze under thick snow fall during winter. Typical separation between denser ice layers is 1 to $2 \mathrm{~m}$ in shallow layers in the South Greenland area, corresponding to the average annual snow fall. At larger depth, the snow ice layers are packed

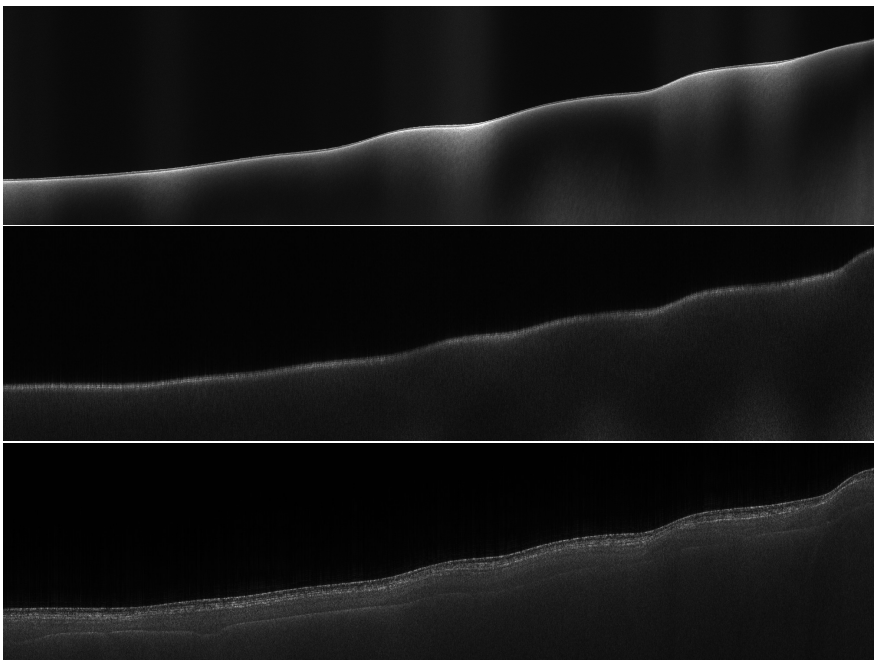

Fig. 5. Nadir (sounding mode) SAR images of the ice-shelf at search zone $\mathrm{X}$ band (top), L band (middle), UHF band (bottom). Along track (horizontal) length is $10 \mathrm{~km}$. Vertical span of images corresponds to $300 \mathrm{~m}$ in vacuum. Top (X-band) profile is acquired $200 \mathrm{~m}$ North of the bottom two ( $\mathrm{L}$ and UHF-band), hence its slightly different shape.

under upper layer weight, and the snow/ice mix turns to solid ice.

At X-band (fig. 5 top), the most salient feature is a strong discontinuity at an apparent depth of $2 \mathrm{~m}$ (the depth/range resolution is around $20 \mathrm{~cm}$ in vacuum). This is most probably the transition between the fresh snow fallen during the winter (acquisition is made early April, when temperature is still well below $0^{\circ} \mathrm{C}$ ) and the firn (snow older than the previous summer that has melt, percolated and refrozen). The actual depth of this snow/firn transition is shallower than the apparent $2 \mathrm{~m}$ because inside the snow/ice cover, the wave propagation is slower, and the depth appears scaled up by the media index, which is 1.25 to 1.35 is the upper layer and increases in the firn to eventually saturate at 1.76 in the solid ice at large depth.

At X-band no more detail appear below the snow/firn discontinuity. At L-band, due to the poor resolution $(1 \mathrm{~m}$ in vacuum) the snow/firn discontinuity is hardly visible (this confirms that resolution/penetration trade-off is not favourable to L-band). At UHF-band, with both a better depth/range resolution ( $63 \mathrm{~cm}$ in vacuum) and better penetration capability, several discontinuities are visible up to an apparent depth of $38 \mathrm{~m}$. It is difficult to convert apparent depth to actual (index compensated) depth below the upper fresh snow layer (the evolution of density with depth depends on the history of snow fall rates and thaw/refreeze events) but a rule of thumb estimate to 25 to $30 \mathrm{~m}$ for the lower discontinuity should indicate an age of 10 to 15 years (under that hypothesis, the great meltdown of the summer of 2012 should be about half way up from this layer).

\section{PEnEtration ASSESSMENT FROM SIDE LOOKING (NORMAL) MODE}

The increase of penetration depth at lower frequency is obvious from the side looking stripmap SAR images (fig. 6). 

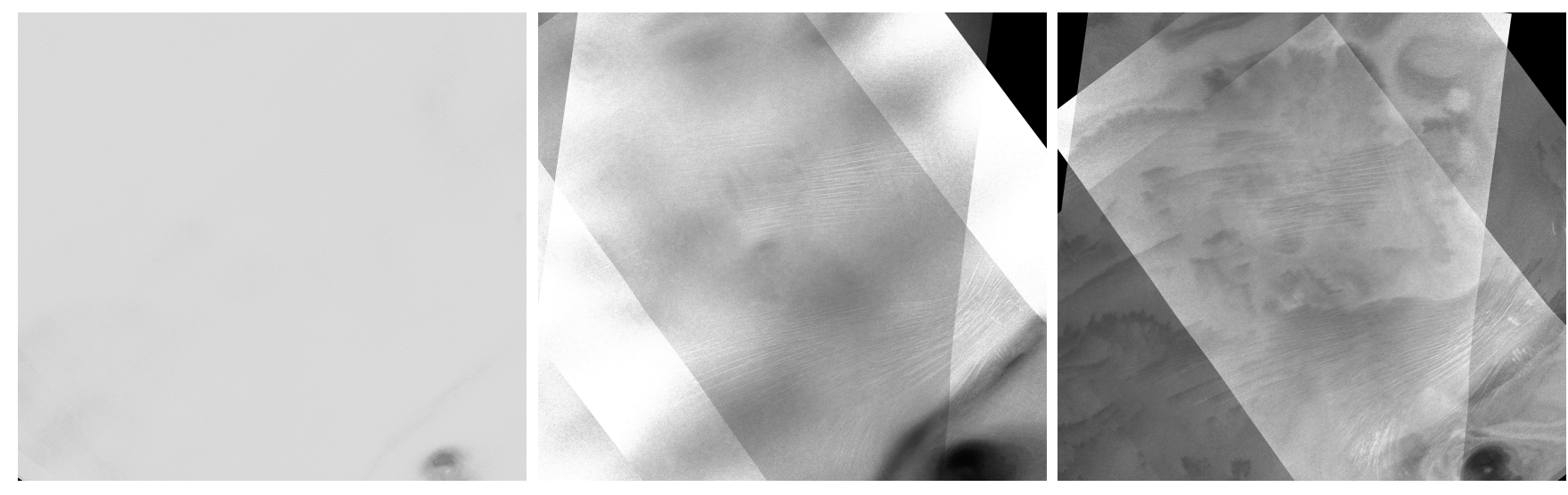

Fig. 6. Side looking SAR image composites of the search zone at X-bande (left), L-band (middle) and UHF-band (right). X-band image is the composite of all polarisation and all acquisitions, a total of 432 single look images. L and UHF-band images are preliminary composite of only $3 \mathrm{H}$ polarisation images without accurate antenna orientation tuning (these two images will be replaced with complete composite in the final paper).

X-band image (left) shows only surface and shallow (1 to 2 meter below surface) features. The darker thick line at the South-West (bottom left on figure) corner is an ice cascade, an area where solid ice rise near or up to the surface. The darker circular feature is the frozen remnant of a recent summer meltwater lake (probably of 2017 or 2016). The crevices apparent above these two features have an air cavity covered by a snow bridge approximatively $2 \mathrm{~m}$ thick (observation made by the GEUS team in situ).

On the L-band image, more crevices are visible on the North of area. These crevices are much older and deeper: their air cavity is covered by approximatively $40 \mathrm{~m}$ of snow/ice. Deeper feature can be slightly visible elsewhere. They have a fuzzy aspect due strong diffusion through the thick layer above them (on fig. 6 middle, they are a bit obscured by the poor antenna pattern compensation, but this should not be so in the final paper).

The UHF-band image shows details at a depth around $65 \mathrm{~m}$ where liquid water fills the crevices bottom and percolates horizontally above denser ice.

Some (3 out of 8 headings) L+UHF acquisitions were repeated for interferometry with $300 \mathrm{~m}$ and $50 \mathrm{~m}$ baselines. The low coherency of L-band interferometry with $300 \mathrm{~m}$ vertical baseline (intended to UHF target depth assessment) corroborates the penetration of L-band for more than $3 \mathrm{~m}$.

\section{A. Observation of target setup on side looking images}

The RCS of the ice-shelf is, as expected, high: at X-band, it ranges on the side look images from $-3 \mathrm{dBm}^{2} / \mathrm{m}^{2}$ at $65^{\circ}$ incident angle up to $+1 \mathrm{dBm}^{2} / \mathrm{m}^{2}$ at $25^{\circ}$ incident angle (for comparison, it is about $7 \mathrm{~dB}$ above the RCS of a typical temperate forest). The decreasing RCS $\left(\gamma_{0}\right)$ with incident angle (with simultaneous increase of the cross-pol/co-pol ratio) is typical of volume scattering media [3].

The corner reflector (with a peak RCS of $+26.7 \mathrm{dBm}^{2}$ in vacuum at $\mathrm{X}$-band) was not salient in the image as expected: Its RCS was attenuated between 25 to $35 \mathrm{~dB}$ in horizontal polarisation and more than $27 \mathrm{~dB}$ in vertical polarisation! The
Luneburg lens was salient in the first X-band acquisition flight (probably because it was not yet completely covered with snow), but was attenuated 32 to $38 \mathrm{~dB}$ on the second X-band flight, after a significant snow fall (the Luneburg lens was eventually recovered under $50 \mathrm{~cm}$ of fresh snow at the end of the campaign). Furthermore, its image appear duplicated on the latter images (fig. 7).
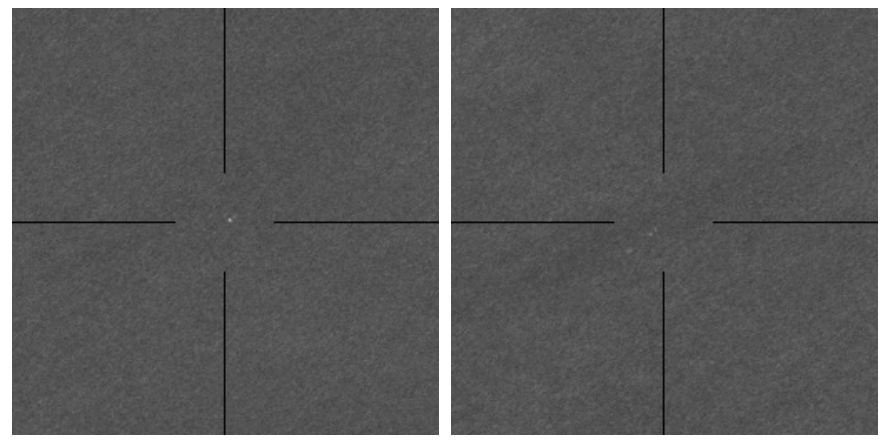

Fig. 7. X-band span images (6 looks $\times 4$ polarisations) of the Luneburg lens probably when not completely covered with snow (left) and later probably completely covered (right).

The reason to both the lower echo and its duplication is probably that the Luneburg lens is designed to be a strong point like reflector when in air or vacuum (atmosphere index at sea level is typically 1.0003) but not when in a media with an higher index (index of fresh snow is typically 1.3). The snow/sphere interface makes a diverging dioptre that turns the lens far-sighted, which completely ruins its RCS. Furthermore, this snow/sphere interface acts as a low index (1) bubble in the (1.3 index) snow, hence induces an echo at its tip (the "normal" echo of the lens is slightly further than the opposite tip of the sphere).

The drastic decrease of the corner reflector was found later consistent with observation of "disappearance" of corner reflectors set up above a glacier after a strong snow storm. It seems that when snow is poured inside a corner reflector, the inhomogeneities of the snow between the reflector faces sort 
of ruins the flatness and the orthogonality of the faces and reduce the RCS to that of a sphere of similar size. When a corner reflector is buried in a flat walled cavity under the snow, its RCS is only reduced by the attenuation factor of the snow (it is how the snow attenuation can be measured).

For engine fragments, however, we could expect the RCS attenuation by snow to be closer to that of the corner reflector in cavity. Indeed, the fan axis fragment set up on the was detected at around $-23 \mathrm{dBm}^{2}$, thus with an attenuation, with respect to observation in air, around $7 \mathrm{~dB}$.

\section{MASSiVe MUlTILOOKING FOR SHALlOW TARGET DETECTION}

The search area was imaged from 4 headings, with 2 antenna pointing and, in each heading, along 3 parallel tracks. Furthermore acquisitions of two headings were repeated for performing repeat-pass interferometry to assess burial depth for target candidates. However, the strong volume scattering induced incoherency between the to images even a small baseline. This ruined the possibility to use interferometry for the intended depth assessment, however, multilooking the two acquisitions effectively decreases the speckle.

With the expected low target/clutter return ratio, the damping of the speckle was a critical point, hence we computed a span (sum of all 4 polar channels) composite of all the looks possible from all acquisitions at X-band - a total of 432 single look complex images (SLC) - in order to minimise the speckle.

However, because we combine images from significantly different incident angles and headings, we need to compensate the stereo effect. For that purpose, we used composite from the same incident angle \& heading (from 24 or 72 SLC images) and matched known F-HPJE engine fragment to derive an apparent depth used for registering the 432 SLC images for the X-band composite.

In fact, two different apparent depths were used: $3.4 \mathrm{~m}$ for the first acquisition flight at $60^{\circ}$ incidence, and $1.9 \mathrm{~m}$ for the second acquisition flight at $40^{\circ}$ incidence (and also an average ice drift estimation between the two flights was used in the registration).

The fact that the apparent depth is shallower at the second acquisition, while the actual depth increased (because of the significant snow fall) is not a mistake: indeed, at the opposite of the effect of refraction on view (e.g. when object appear shallower than they actually are in a river), the refraction effect in radar is to scale up the depth, alter the along view horizontal position and defocus (blur) the target image. Furthermore, the depth scaling increases with incident angle. Simplistic geometrical optics simulations show that, for the typical (1.3) index of upper snow layers, the horizontal alteration for 1 or $2 \mathrm{~m}$ depth is less than the resolution $(20 \mathrm{~cm})$ at $\mathrm{X}$-band and the defocusing becomes only significant at much larger depth (typ. 50 to $100 \mathrm{~m}$ ). Hence the SLC images can be mapped to a common frame as if they were acquired through air only (no snow) at a lower (apparent depth) altitude.

Of course, object with actual depth significantly different from that of the known engine fragment would not match between each SLC on the final composite, and appear as a cluster of separate echoes (this is the case for the Luneburg Lens for the first acquisition flight, because the lens was set up half buried at the surface and not $1.3 \mathrm{~m}$ below surface). However, echoes should match for an object at the fragment depth, thus allowing detection of low RCS engine fragments, especially in area where the effective number of look (ENL) of the composite is very high (hence the speckle very low).

In order to minimise the speckle (maximise the ENL), we computed 6 looks extending to the edge of the antenna main lobe. The consequence is that the ratio signal over noise and ambiguity varies drastically between the SLC images combined into the composite. For example, a look computed in the middle of the antenna main lobe yields thermal \& system noise about $20 \mathrm{~dB}$ below the clutter, but a look computed at the edge of the main lobe, the antenna pattern is about $15 \%$ of the peak value, and the Doppler ambiguities are 7 times higher. Thus we combine SLC with marginal $(0.5 \%)$ noise+ambiguities (such as a look in the middle of the antenna pattern) and SLC with very significant (around 50\%) noise+ambiguities. The combination law is derived from [4] with the extra twist that the clutter RCS is known (instead of being iteratively estimated) and that the ambiguities for reciprocal cross-polar channels ( $\mathrm{Hv}$ and $\mathrm{Vh})$ are coherent, hence is not damped (unlike noise) when combining reciprocal cross-polar SLC images.

Fig. 8-left shows a detail at native X-band resolution $(20 \mathrm{~cm})$ of the full 432-looks composite. The $200 \times 265 \mathrm{~m}$ area is selected with shallow crevices for illustration (fig. 2-right is also a detail from the same composite).

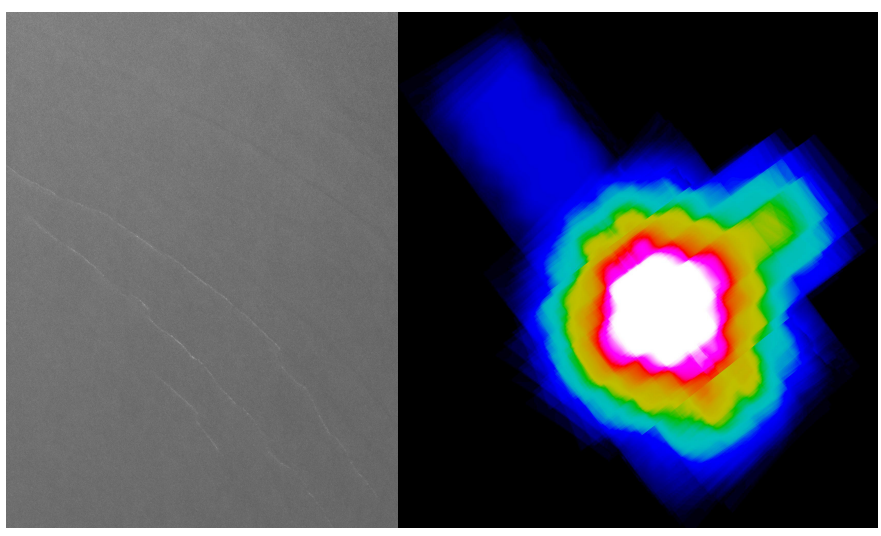

Fig. 8. Sample of composite image at $\mathrm{X}$ band showing very low clutter speckle (left). Equivalent number of looks for the full work zone number 2 (right, false colour: yellow $=100$ looks, white= above 200 looks).

On the fig. 8-right, the ENL for all looks of all 18 acquisitions at X-band is given for the full area imaged (the scale is 100 times larger than the detail on the left, the full area is $20 \times 20 \mathrm{~km}$.

To illustrate the detection of targets of low RCS, fig. 9 shows the detection of the two setup targets of lowest RCS (the ice filled sled emulating an ice lens and the empty hole refilled 
with packed snow). On the left of the window is the composite image, and on the right the detections (detection filter is a CFAR filter on the rms amplitude averaged in a 3times 3 window).

If the forecoming ground mission for fragment recovery yields engine fragments at the detected candidate positions, the final version of the article will be updated to report this.

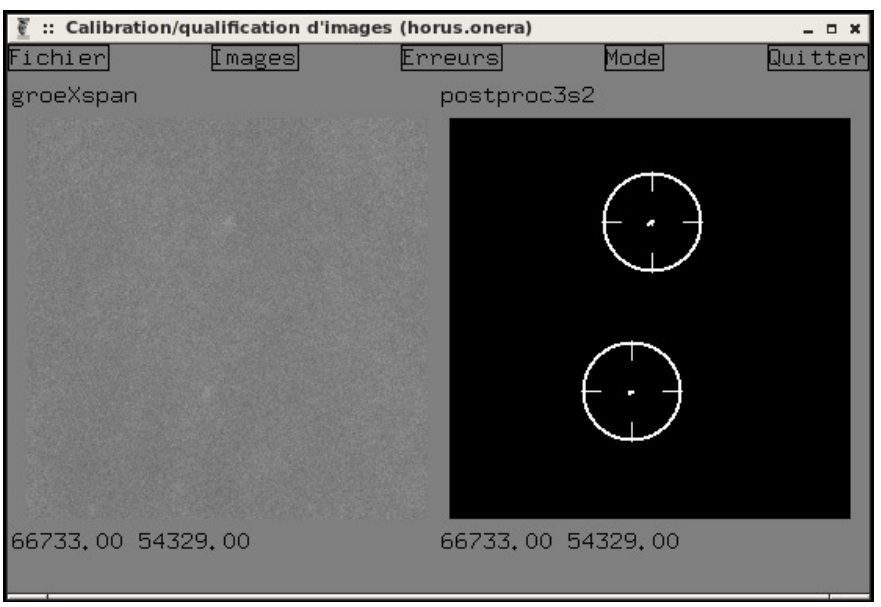

Fig. 9. Detection of the target setup ice lens (plastic sled filled with ice at the top of the window) and an empty hole packed with snow (bottom) on a composite image of all acquired $\mathrm{X}$ band images.

\section{CONCLUSION}

Airborne SAR imaging at $\mathrm{X}$ and UHF-bands proved a valuable tool for ice-shelf subsurface investigations. Remote detection of large features at UHF-band up to a depth of approximatively $50 \mathrm{~m}$ and of smaller objects at X-band up to a depth of $3 \mathrm{~m}$ are possible. However, this requires a large number of acquisitions and a significant computation cost in order to yield results comparable to surface measurements with ground penetrating radar (GPR). But this technique allows a much larger surface to be acquired: Our acquisition campaign lasted 2 weeks in Greenland, while the coverage of less than $5 \%$ of the area of fig. 6 with a GPS required 3 weeks of work at the surface (under sometimes drastic meteorological conditions).

With the snow accumulation rate on the North ice-shelves (1 to $2 \mathrm{~m} / \mathrm{yrs}$ ), this means that the airborne SAR technique has a visibility horizon of a couple of years at X-band for small objects, and around 30 years for larger objects at UHF band. This is consistent with recent attempts at UHF band [5] to detect the WW2 "lost squadron" of which present depth is estimated at around $100 \mathrm{~m}$, which only revealed (relatively) shallower traces of the excavation made in 1992 for recovering one of the aircraft.

\section{REFERENCES}

[1] D. Campbell, J. Chandler, S. Ostro, G. Pettengill, and I. Shapiro, "Galilean satellites: 1976 radar results," Icarus, vol. 34, no. 2, pp. 254267, 1978.
[2] J. Dall, "Insar elevation bias caused by penetration into uniform volumes," IEEE Transactions on Geoscience and Remote Sensing, vol. 45(7), pp. 2319-2324, November 2007.

[3] V. Tishkovets, P. Litvinov, and M. Lyubchenko, "Coherent opposition effects for semi-infinite discrete random medium in the double-scattering approximation," Journal of Quantitative Spectroscopy and Radiative Transfer, vol. 72, no. 6, pp. $803-811,2002$.

[4] H. Cantalloube and C. Nahum, "How to compute a multi-look sar image?" in CEOS SAR Workshop, Toulouse, France 26-29 Oct 1999, E. special publications, Ed., vol. 450, 2000, pp. 635-640.

[5] E. Krogager, "Results from the daloex 2015 campaign with f-sar in greenland," vol. 2018-June, 2018, pp. 608-613. 